\title{
A gestão da agricultura familiar: pluriatividade, diversificação da produção e agricultura orgânica: um estudo de caso da região da campanha
}

\author{
Otomar Vielmo ${ }^{1}$ \\ Elisabeth Cristina Drumm² \\ Cidonea Machado Deponti ${ }^{3}$
}

\begin{abstract}
Resumo
Este artigo analisa a gestão combinada das práticas de pluriatividade, de diversificação da produção e de agricultura orgânica e sua contribuição para o desenvolvimento rural da propriedade familiar. A justificativa do presente estudo decorre da carência, no âmbito da literatura, de trabalhos que relacionem as três categorias abordadas. A investigação desenvolveu-se por meio de uma pesquisa qualitativa exploratória, em um estudo de caso, o qual foi definido por uma amostragem não probabilística, ou seja, intencional. Para a coleta de dados, utilizaram-se uma entrevista não estruturada e a observação simples. Na sequência, os dados foram analisados de acordo com a técnica da grounded theory em conjunto com uma triangulação de dados entre conceitos, observações realizadas e fala dos entrevistados. O caso estudado é uma propriedade familiar, produtora de alimentos orgânicos, localizada no município de Santiago - RS, na qual o trabalho e a administração são realizados pela própria família. Este caso foi escolhido por se observar, na propriedade, traços da ocorrência das categorias objeto do estudo. Os resultados da pesquisa apontaram para um contexto em que as três práticas combinadas contribuem, principalmente, para a geração de renda e a estabilidade econômico-financeira da família, que, somadas a uma gestão devidamente planejada, organizada, estruturada e controlada, permite que a produção seja otimizada, e os riscos minimizados.
\end{abstract}

Palavras-chave: Gestão da Agricultura Familiar. Pluriatividade. Diversificação da Produção. Agricultura Orgânica.

\begin{abstract}
This article analyzes the management management of plural-activity, diversification of production and organic agriculture impacts the development of family property. The rationale of this study stems from the lack, in literature, in studies that relate the three covered categories. The research was developed through an exploratory qualitative research, a case study, which was defined by an unintentional probabilistic sampling. For data collection we used an unstructured interview and simple observation, following the data were analyzed according to grounded theory technique in conjunction with a triangulation of data between concepts, observations and talks of respondents. The case study is a family owned producer of organic food, in the municipality of Santiago - RS, in which work and administration are carried out by the family. This case was chosen by observing the occurrence of traces of the study of object categories on your property. The survey results pointed to a context in which the three practices combined mainly contribute to income generation and economic-financial stability of the family, and that his management be properly planned, organized, structured and controlled, in order to optimize production and minimize risks.
\end{abstract}

Keywords: Family Farming Management. Plural-activity. Diversification of Production. Organic Agriculture.

\section{Introdução}

As discussões que cerceiam a agricultura familiar tomam cada vez mais força nos dias atuais. É provável que isso ocorra no Brasil como fruto do incentivo a essa categoria, principalmente por parte do governo, que, em suas políticas públicas voltadas para a área rural, tem facilitado em muito o trabalho do agricultor familiar. Mas, além das discussões acerca de

\footnotetext{
${ }^{1}$ Graduado em Administração pela Universidade da Região da Campanha (URCAMP). otomarvielmo@gmail.com.

${ }^{2}$ Professora na Universidade da URCAMP. Doutoranda em Desenvolvimento Regional (PPGDR/UNISC). elisabethdrumm@gmail.com.

${ }^{3}$ Professora do Programa de Pós-Graduação em Desenvolvimento Regional da Universidade de Santa Cruz do Sul (UNISC) e Pós-Doutora em Sociologia do Desenvolvimento pela Universidade Federal do Rio Grande do Sul (UFRGS), Doutora em Desenvolvimento Rural (UFRGS). cidonea@unisc.br.
} 
incentivos e de políticas públicas, existem outras de teor científico, que buscam entender alguns fenômenos relacionados a esse tipo de agricultura e que vão desde discussões sobre melhoramento de produção até temas de cunho social e econômico.

O papel que essa categoria vem desempenhando na sociedade foge aos limites da produção para consumo próprio e passa a integrar um contexto em que a produção é orientada para a comercialização. Esse contexto, unido à necessidade de geração de renda para a família, faz com que surjam alguns conceitos de cunho socioeconômico, como, por exemplo, a pluriatividade, a agricultura orgânica e a diversificação da produção.

O presente artigo entra no campo das discussões sobre a gestão da agricultura familiar, e sua problemática consiste em compreender como a gestão combinada das práticas de pluriatividade, de diversificação da produção e de agricultura orgânica contribuem no desempenho da propriedade familiar. A fim de responder a essa problemática, julga-se necessário definir os conceitos das práticas estudadas, analisar o funcionamento em sua concepção prática e estudar as principais contribuições da gestão combinada e integrada desses sistemas de trabalho.

O trabalho justifica-se pelo fato de que, embora se observem, na literatura atual, estudos sobre os temas abordados, não há neles a combinação entre a pluriatividade, a diversificação da produção e a agricultura orgânica.

O presente estudo desenvolveu-se por meio de uma pesquisa qualitativa e exploratória, a fim de buscar análises mais profundas em relação aos fenômenos estudados e torná-los claros na investigação proposta. Do ponto de vista dos procedimentos, a pesquisa enquadra-se em um estudo de caso, o qual foi definido por meio de uma amostragem não probabilística, ou seja, intencional. Os instrumentos de coleta de dados utilizados na pesquisa foram a entrevista não estruturada e a observação simples. Os dados foram analisados conforme a técnica da Grounded Theory, além da triangulação dos conceitos abordados, das observações realizadas e do depoimento dos entrevistados. O caso estudado é uma propriedade familiar, produtora de alimentos orgânicos, localizada no interior do município de Santiago, no estado do Rio Grande do Sul.

O trabalho está dividido em sete seções, além da introdução e das considerações finais. No primeiro, aborda-se o conceito de agricultura familiar. Do segundo ao quinto, desenvolve-se a revisão de literatura sobre pluriatividade, diversificação da produção e agricultura orgânica e gestão das propriedades rurais familiares. O sexto trata dos procedimentos metodológicos, e o sétimo, da análise dos resultados.

\section{A agricultura familiar enquanto categoria social}

De acordo com Schneider (2003), em meados da década de 1990, houve um movimento por parte dos estudiosos que simbolizou uma retomada acerca dos estudos na área rural. Esses estudos passaram a trazer uma ênfase maior a questões sobre sustentabilidade e de cunho ambiental, bem como trouxeram à tona a categoria agricultura familiar.

Conforme expõe Stoffel (2013), apesar dessa ênfase no país dar-se na metade dos anos de 1990 e de haver uma forte inserção da expressão "agricultura familiar" no contexto 
rural, esta não é uma categoria que surgiu nesse período, mas seu surgimento, na região Sul, por exemplo, inicia com a ocupação dessa área pelos colonizadores de origem açoriana, alemã e italiana, que, na época, desenvolviam o trabalho em suas propriedades, utilizando a mão de obra da própria família, visando a uma produção agropecuária que lhes provesse sustento e uma possível geração de renda.

A fim de facilitar o entendimento da agricultura familiar, considera-se interessante conhecer, primeiramente, o conceito de propriedade familiar, que, de acordo com a Lei no 4.504, de 30 de novembro de 1964, inciso II, do Art. 4으, capítulo I, é:

o imóvel rural que, direta e pessoalmente explorado pelo agricultor e sua família, Ihes absorva toda a força de trabalho, garantindo-lhes a subsistência e o progresso social e econômico, com área máxima fixada para cada região e tipo de exploração, e eventualmente trabalho com a ajuda de terceiros (BRASIL, 1964).

A partir do conceito de propriedade familiar, aborda-se o conceito de agricultura familiar, no qual Schneider (2003) afirma que sua manifestação nos meios social, político e acadêmico, no que diz respeito aos discursos por parte governamental ou de movimentos ligados ao campo, tem ganhado mais espaço e ocorrido com mais frequência no Brasil. Esse conceito teve seu surgimento no país na década de 1990, quando, em meio ao cenário desafiador que o sindicalismo rural enfrentava na época, trouxe proteção e apoio ( p. 100 ): "[...] a um conjunto de categorias sociais, como, por exemplo, assentados, arrendatários, parceiros, integrados às agroindústrias, entre outros, que não mais podiam ser confortavelmente identificados com as noções de pequenos produtores [...]".

Funk (2008) mostra que, contrariando o pensamento de vários autores que julgavam a agricultura familiar como uma categoria em extinção frente ao modo de produção capitalista, esta tem se desenvolvido e se adaptado a esse meio de tal forma que vem persistindo, ao longo de décadas, e com um crescimento considerável. Isso se deve à capacidade de adaptar-se rapidamente às mudanças impostas pelo contexto socioeconômico, à qual se associa a capacidade de decidir o que vai produzir e como o fará, pois essa categoria permite uma proximidade muito grande entre a gestão e a produção, em consequência de o trabalho ser desenvolvido pela família que gera o negócio.

Em relação à agricultura familiar, os estudos sobre a sua definição indicam que "[...] é o modo agrícola pelo qual mais se produz alimentos no Brasil, já que possui uma produção diversificada, destinada ao abastecimento da propriedade, onde o excedente é vendido com vistas à obtenção de renda" (FUNK; BORGES; SALAMONI, 2006, p. 2). Segundo os autores, a abrangência que a agricultura familiar tem tomado, nos últimos anos, faz com que tenha ares de novidade e de renovação, embora não seja uma atividade nova.

Ainda, de acordo com Funk (2008, p. 26), a caracterização das economias agrícolas familiares dá-se por alguns princípios, "[...] pois se organizam sobre seus próprios meios de trabalho, onde quem movimenta o processo é o próprio dono dos meios de produção", ou seja, "[...] a agricultura familiar representa um modelo produtivo de tal forma peculiar, que diversos estudos procedem a uma delimitação própria" (BROSE, 1999, p. 102).

Conforme Jean (1994), o agricultor moderno apresenta uma tríplice identidade: proprietário fundiário, empresário privado e trabalhador. "Este personagem trinitário que é o 
agricultor moderno teve que doar a renda fundiária e o lucro capitalista à economia e à sociedade, para sobreviver, buscando apenas um salário mínimo para subsistir" (JEAN, 1994, p. 5).

A legislação que estabelece as diretrizes para a formulação da política nacional da agricultura familiar refere-se ao agricultor familiar da seguinte forma:

\footnotetext{
Art. 3o Para os efeitos desta Lei, considera-se agricultor familiar e empreendedor familiar rural aquele que pratica atividades no meio rural, atendendo, simultaneamente, aos seguintes requisitos:

I - não detenha, a qualquer título, área maior do que 4 (quatro) módulos fiscais;

II - utilize, predominantemente, mão de obra da própria família nas atividades econômicas do seu estabelecimento ou empreendimento;

III - tenha renda familiar predominantemente originada de atividades econômicas vinculadas ao próprio estabelecimento ou empreendimento;

IV - dirija seu estabelecimento ou empreendimento com sua família. (BRASIL 2006).
}

Nesse contexto, Tedesco (1999) explica que a agricultura familiar é aquela na qual a família é proprietária dos meios de produção e, simultaneamente, é quem executa o trabalho necessário ao funcionamento da propriedade. O questionamento central de Tedesco relacionase à explicação teórica da permanência do agricultor familiar e de suas estratégias de sobrevivência e reprodução na sociedade moderna.

Dessa forma, Brose (1999) afirma que, segundo algumas características gerais delimitadas pela FAO (Organização das Nações Unidas para a Alimentação e a Agricultura), pode-se definir a agricultura familiar, sendo elas:

a) A gestão da unidade produtiva é realizada por pessoas que mantêm entre si laços de parentesco e/ou casamento.

b) A maior parte do trabalho é realizada por membros da família.

c) Os meios de produção (embora nem sempre a terra) pertencem à família.

Funk (2008) entende que o desenvolvimento da maioria dos municípios do país sofre impacto da agricultura familiar, pois essa categoria interfere em setores como o comercial, o industrial e o de serviços. Isso se dá pelo fato de que a agricultura familiar é responsável por parte da geração de emprego e de renda locais e pela produção de alimentos, e é considerada a principal força de impulsão do desenvolvimento desses municípios.

Deponti (2006) refere que Wanderley (1999) defende que o agricultor familiar brasileiro não é um personagem passivo, pois, ao longo da história, tem buscado, com suas forças, traçar estratégias para lutar por seu espaço, adaptando-se às exigências da agricultura moderna sem perder os traços camponeses. Por isso, aliás, afirma a autora, que o conceito de camponês é ressemantizado, na medida em que recorre a sua experiência camponesa, demonstrando a sua capacidade de resistência e de adaptação às transformações mais gerais da sociedade.

Em síntese, entende-se que a agricultura familiar é uma categoria que se caracteriza por ser desenvolvida geralmente por um grupo de pessoas que tem um vínculo de parentesco, utiliza seus próprios meios de produção e cujo trabalho é realizado pela própria família. É evidente que a agricultura familiar tem grande importância no contexto socioeconômico, fruto de uma evolução histórica peculiar, por meio da qual desenvolveu características, métodos e técnicas de produção e de gestão, as quais se refletem em uma produção rica, diversificada e que torna essa categoria a maior produtora de alimentos do país. 
Nesse contexto, na sequência, serão abordados alguns conceitos que fazem parte do estudo da agricultura familiar e estão intimamente ligados a essa categoria. Esses conceitos são reflexos de alguns fenômenos que ocorrem nas formas de trabalho das propriedades familiares e expõem ideias como agroecologia, sustentabilidade, união de atividades agrícolas e nãoagrícolas no meio rural, entre outras.

\section{A pluriatividade}

Schneider (2003, p. 100) aborda que, a partir da segunda metade da década de 1990, os estudiosos passam a investigar e a pesquisar novos temas dentro do espaço rural. As pesquisas ultrapassam a temática da agricultura familiar e seguem linhas de pensamento que “[...] talvez esteja $(m)$ relacionada(s) à insistente afirmação de que não se pode mais confundir, ou interpretar como sinônimos o espaço rural e as atividades produtivas ali desempenhadas".

Conforme aponta Schneider (2003), a partir desse período, houve uma projeção dos estudos acerca do fato de que não apenas a agricultura compõe a vida no campo, mas que ela própria vem sendo entendida como uma das dimensões do meio rural. Isso se retrata na ocorrência de situações em que alguns membros do grupo familiar passam a dedicar-se a outras atividades que não à prática agrícola, enfatizando a ocorrência de atividades nãoagrícolas ligadas ao meio rural, o que caracteriza a pluriatividade.

O autor enfatiza que, embora a pluriatividade seja uma categoria nova no âmbito dos estudos, em decorrência dos quais tenha recebido essa nomenclatura, as atividades que a caracterizam preexistem aos seus estudos no contexto conceitual. Ainda, segundo Kautsky (apud SCHNEIDER, 2003), as propriedades desempenhavam o que o autor chama de "formas de trabalho acessório", alegando que essas formas de trabalho proporcionam às famílias o desenvolvimento social. Entre as formas de trabalho acessório abordadas pelo autor estão o trabalho temporário, desenvolvido de forma assalariada em propriedades maiores, e a ocupação de membros do grupo familiar em indústrias no campo, como forma paralela de obtenção de renda.

De acordo com Schneider et al. (2006, p. 2), a ideia de pluriatividade vem sendo utilizada por pesquisadores, a fim de analisar e de explicar o processo de diversificação do trabalho que vem ocorrendo nas unidades de produção familiar. Para os autores, "[...] a pluriatividade refere-se a um fenômeno que se caracteriza pela combinação das múltiplas inserções ocupacionais das pessoas que pertencem a uma mesma família", ou seja, diz respeito a um fenômeno em que se combinam pelo menos duas atividades, sendo uma delas a agricultura. Essas atividades são exercidas por um grupo familiar que tenha ou não entre si laços consanguíneos, mas que se consideram, ou denominam, uma família, compartilhando um mesmo espaço de moradia (SCHNEIDER, 2009).

Schneider et al. (2006, p. 3) ainda apontam que a pluriatividade é heterogênea e diversificada, e está ligada, "[...] de um lado, às estratégias sociais e produtivas que vierem a ser adotadas pela família e por seus membros e, de outro, dependerá das características do contexto em que estiverem inseridas". É por meio dela que as famílias de agricultores que residem no meio rural "[...] optam pelo exercício de diferentes atividades, ou, ainda, optam 
pelo exercício de atividades não agrícolas, mantendo a moradia no campo e uma ligação, inclusive produtiva, com a agricultura e a vida no espaço rural" (PIRES; SPRICIGO, s/d, p. 1-2).

Considera-se que "[...] é no âmbito da família que se discute e se organiza a inserção produtiva, laboral e moral de seus diferentes membros e em função deste referencial que se estabelecem as estratégias individuais e coletivas que garantem a reprodução social do grupo" (SCHNEIDER apud AZAMBUJA 2006, p. 57).

\begin{abstract}
Mas a definição operacional da pluriatividade também requer a referência a uma unidade de análise a ser utilizada. A rigor, pode-se falar da pluriatividade de uma pessoa, quando esta exerce mais de uma atividade, ou da pluriatividade de uma família ou ainda de parte dos membros que integram a família. Nos trabalhos que temos realizado, a pluriatividade sempre se refere à família, pois consideramos pluriativa ${ }^{4}$ a família em que pelo menos um dos membros que a integra exerce a combinação de atividades agrícolas, para-agrícolas e não-agrícolas. Trata-se, portanto, da pluriatividade familiar que ocorre nos espaços rurais (SCHNEIDER, 2009, p. 5).
\end{abstract}

Schneider (2009) diz que as atividades agrícolas são compostas por um conjunto de tarefas, procedimentos e operações em que se cultivam organismos vivos, tanto vegetais quanto animais, ocorrendo um gerenciamento de processos biológicos que visam à produção de alimentos. Nessa concepção, o entendimento acerca das atividades para-agrícolas refere-se a um conjunto de processos e de operações que levam à transformação ou beneficiamento da produção agrícola, conforme Schneider (2009). No que se refere às atividades não-agrícolas, o autor ressalta que são todas as atividades que não estejam compreendidas nos conceitos de agrícola ou para-agrícola, podendo ser atividades que envolvam comércio, indústria ou serviços.

Complementando, Azambuja (2006, p. 39) ratifica essa posição, ressaltando que é considerada "[...] pluriativa a família em que pelo menos um dos seus membros esteja ocupado em atividade estranha à agricultura". No entanto, Schneider $(2009$, p. 5) considera importante observar que apenas o fato de uma família possuir diversas rendas advindas, por exemplo, de aposentadorias ou de membros e parentes que não trabalham no estabelecimento, não caracteriza a pluriatividade, pois, para tal, é necessário "[...] se configurar uma situação que implique na combinação de diferentes atividades com a agricultura".

Schneider et al. $(2006$, p. 3 ) entendem que "[...] a pluriatividade manifesta-se naquelas situações em que a integração dos membros das famílias de agricultores aos mercados passa a ocorrer, também, pela via do mercado de trabalho". Essa concepção ocorre, principalmente, quando a integração da produção com o mercado de bens e de serviços ainda é principiante, e a mão de obra tornar-se mercadoria de troca. Portanto, além de inserir o grupo familiar em um mercado de produtos, a pluriatividade permite, também, a inserção de sua mão de obra no mercado de trabalho, de forma concomitante ou distinta, defendem os autores.

É interessante prestar atenção em uma ressalva feita por Schneider et al. (2006), em relação ao entendimento da pluriatividade, pois não pode haver confusão entre os conceitos de categoria e de atividades não-agrícolas. O autor deixa claro que a pluriatividade ocorre apenas quando há a combinação de atividades não agrícolas com agrícolas, pois a família ou membros dela podem "[...] escolher pela troca de ocupação, deixando o trabalho agrícola e passando a

\footnotetext{
${ }^{4}$ Neologismo apresentado pelo autor.
} 
ocupar-se exclusivamente de atividades não agrícolas, mesmo sem deixar de residir no meio rural" (SCHNEIDER et al., 2006, p. 5).

Conforme explica Schneider (2009, p. 7), a discussão sobre pluriatividade situa-se no contexto do desenvolvimento rural e, além de ser uma estratégia para a agricultura familiar, “[...] poderá contribuir de forma decisiva para ajudar a solucionar dificuldades e restrições que afetam as populações rurais, tais como a geração de emprego, o acesso à renda e sua estabilização, a oferta de oportunidades para jovens, entre outros".

A concepção de pluriatividade e os contextos nos quais se insere geraram uma gama de estudos, nos quais, Schneider (2009) aponta, pode-se distinguir essa categoria segundo algumas tipologias. Essas tipologias, na pluriatividade, ocorrem em decorrência das mais distintas causas que podem gerá-las. Nessa linha de pensamento, o autor sugere quatro tipos distintos de pluriatividade, a saber: a tradicional, a intersetorial, a de base agrária e a para-agrícola.

Por pluriatividade tradicional, Schneider (2009) trata aquela que ocorre dentro da propriedade e que visa a uma produção para o autoconsumo, envolvendo produção, transformação e artesanato, com o objetivo de produzir peças que possam ser utilizadas no próprio meio para desenvolver as atividades referentes ao trabalho da propriedade. $\mathrm{O}$ autor deixa claro que essa é uma tipologia "[...] que sempre existiu e caracteriza de forma genuína as unidades de produção familiares no meio rural" (SCHNEIDER, 2009, p. 08). A distinção dessa forma de ocorrência da pluriatividade decorre do fato de que ela não tem objetivos comerciais, e sua existência é dependente do modo de vida e de trabalho do grupo familiar.

Em relação à pluriatividade intersetorial, Schneider (2009, p. 8) aponta que "[...] decorre do processo de encadeamento e de articulação da agricultura com os demais setores da economia, principalmente a indústria e o comércio", como consequência de dois fatores: a descentralização da indústria e a rurbanização ${ }^{5}$. O autor entende que esses processos transformam o meio rural, colocando-o dentro de uma nova dinâmica, cujas principais características são a valorização imobiliária e a prestação de serviços. Em torno disso, Schneider (2009) afirma que há uma homogeneização entre os mercados de trabalho urbano e rural, o que, consequentemente, salienta a pluriatividade das famílias.

A pluriatividade de base agrária é exposta por Schneider (2009) como sendo um processo decorrente da modernização da agricultura, que ocorre no âmbito do setor agropecuário, combinando atividades agrícolas e novas atividades não-agrícolas. Seu surgimento decorre, principalmente, da terceirização de etapas ou fases da produção, a fim de se utilizar de meios como máquinas e equipamentos para desempenhar o processo produtivo.

De acordo com Schneider (2009, p. 10), a pluriatividade de base agrária pode se manifestar "[...] através dos indivíduos que residem no meio rural e trabalham na atividade agrícola, mas uma parcela relevante, senão a maior parte, de sua jornada de trabalho é dedicada à prestação de serviços". É caracterizada, principalmente, quando um agricultor utiliza suas máquinas e equipamentos para prestar serviços a um vizinho, em troca de dinheiro ou de produtos. Pode ocorrer, também, através da contratação de pessoas que residem no

\footnotetext{
${ }^{5}$ Neologismo apresentado pelo autor para retratar o processo de expansão das áreas de habitação próximas das regiões metropolitanas e o fluxo diário relacionado às pessoas que trabalham em atividades não-agrícolas, mas que residem no meio rural.
} 
meio rural para a realização de atividades de beneficiamento, transporte ou comercialização. Outra forma de manifestação é por meio da venda da força de trabalho, decorrente, principalmente, da sazonalidade na produção que afeta algumas propriedades, resultando na procura, por parte dos agricultores, de serviços temporários que lhes tragam renda extra (SCHNEIDER, 2009).

No que diz respeito à pluriatividade para-agrícola, Schneider (2009) expõe que é aquela em que o grupo familiar ou membros dele se envolvem com atividades e processos destinados ao beneficiamento ou à transformação da produção gerada na propriedade, e/ou adquirida de outrem, mas que se destine à comercialização. Conforme esse tipo de produção cresce e toma vulto "[...] ela se torna uma atividade independente, inaugurando uma nova jornada de trabalho e rotinas diferenciadas, sendo possível afirmar que surge uma nova atividade $^{6}[. . .]^{\prime \prime}(2009$, p. 11). Essa nova atividade, combinada com a agricultura, configura a pluriatividade e está ligada principalmente à produção de carne, leite e frutas, os quais passam a ser beneficiados a fim de agregar valor ao produto.

Em suma, a pluriatividade é uma categoria desenvolvida dentro da agricultura familiar, que consiste em uma diversificação do trabalho, combinando de forma simultânea atividades agrícolas, para-agrícolas e não-agrícolas, ou seja, esse fenômeno ocorre quando um ou mais membros da família ou grupo familiar estão envolvidos com atividades estranhas à agricultura, mas mantendo o vínculo com a mesma, ou que sua força de trabalho esteja sendo empregada além das atividades agrícolas da propriedade, servindo, principalmente, como mercadoria de troca com outras propriedades, visando à obtenção de renda.

Torna-se claro que a pluriatividade pode ser caracterizada de formas distintas, mas que essas formas podem ocorrer - e ocorrem, muitas vezes -, simultaneamente em uma mesma propriedade. Essa integração permite ao grupo familiar adaptar-se conforme suas necessidades, principalmente no que diz respeito à geração de renda, servindo como estratégia de sustentabilidade para a agricultura familiar.

\section{Diversificação da produção}

Para Carvalho (2005, p. 1), “[...] a agricultura sempre teve grande importância dentro da economia nacional. Com o processo de industrialização e de introdução das inovações tecnológicas, a agricultura, de forma geral, tornou-se um ator coadjuvante no processo do desenvolvimento capitalista". As atividades agrícolas tornam-se mais complexas em função de um mercado cada vez mais incerto e dinâmico, criando uma situação em que "[...] a produção agrícola já não é mais a única, e, em muitos casos, nem a principal fonte de renda das famílias que vivem no espaço rural" (CARVALHO, 2005, p. 1).

Atualmente, o setor agrícola brasileiro é muito dependente de recursos externos às propriedades, "[...] o que acaba por confirmar o desenvolvimento capitalista da agricultura e a apropriação industrial de suas atividades" (HAAS, 2008, p. 2). Para a autora, essa situação é decorrente da modernização da agricultura, que vem sendo implantada desde a década de

\footnotetext{
${ }^{6}$ Grifo do autor.
}

COLÓQUIO - Revista do Desenvolvimento Regional - Faccat - Taquara/RS - v. 14, n. 2, jul./dez. 2017 
1960, e do melhoramento tecnológico e genético, o que resultou no uso cada vez maior de fertilizantes e de agrotóxicos. Entretanto, com esse modelo, surgem problemas como redução de mão de obra e maior necessidade de investimentos, que refletem em um aumento de produtividade e maior custo de produção, e, consequentemente, em baixos índices de lucratividade.

Para Haas (2008, p. 2), "[...] os agricultores familiares que detinham sua renda baseada em commodities acabavam por dependerem das variações climáticas, das cotações dos preços de venda internacionais, dos custos dos insumos, entre outros fatores". Esse cenário de dependência, queda nos preços internacionais das "commodities" e aumento dos custos de produção impossibilitou que agricultores familiares continuassem com os mesmos cultivos, iniciando, então, uma diversificação da produção como estratégia para a sua sobrevivência. Essa diversificação é como uma rota de fuga frente aos sistemas de produção especializados.

Funk (2008, p. 39) enfatiza que a agricultura familiar se utiliza dessa estratégia "[...] para diminuir os riscos de perdas totais, racionalizando o uso da mão de obra e tirando o máximo proveito da interação entre diversas culturas e criações". Nessa linha de raciocínio, Fantin (apud HAAS, 2008) observa que uma das principais vantagens na diversificação da produção está no fato de que o produtor não depende apenas de uma cultura, mas de que ele tenha mais de uma alternativa, no caso de ocorrer algum problema, e consiga continuar produzindo outros produtos de forma a manter a sua estabilidade econômico-financeira.

O mesmo pensamento é evidenciado por Carvalho (2005, p. 2), ao dizer que a diversificação agrícola "[...] talvez possa ser uma das maneiras de promover o desenvolvimento da agropecuária familiar para um município ou região e, consequentemente, promover uma melhoria na qualidade de vida desses produtores". Ellis (2000) defende a diversificação produtiva como uma maneira de subsistência das famílias rurais, pois, através da diversificação, as famílias poderão encontrar outras oportunidades para enfrentar os diversos e os desconhecidos obstáculos e vulnerabilidades encontradas.

Ellis (2000) defende a diversificação produtiva como uma maneira de subsistência das famílias rurais, pois, através da diversificação, as famílias poderão encontrar outras oportunidades para enfrentar os diversos e os desconhecidos obstáculos e vulnerabilidades encontradas.

Ellis (2001) ainda destaca alguns determinantes para a diversificação produtiva, tais como sazonalidade, mercado de trabalho, falhas de crédito, estratégia de risco e de ativos, comportamento e adaptação. No entanto, esclarece que esses determinantes constituem forças e processos que conduzem a diversificações distintas, mas que, em determinado momento, podem sobrepor-se.

Em síntese, os estudos indicam que a diversificação da produção é uma estratégia para os agricultores familiares, pois se caracteriza como uma alternativa de sobrevivência em um mercado cada vez mais dinâmico. Trata-se de uma forma encontrada, para escapar da dependência que o mercado impõe e para reduzir os riscos frente a um ambiente de instabilidade em que a agricultura se encontra, estando sempre vulnerável a agentes externos, como o clima, as pragas, as doenças e as variações nas condições de mercado, principalmente 
os preços das "commodities". Além disso, consiste em uma opção para aumentar a renda familiar.

\section{Agricultura orgânica}

Enquanto ciência, a Agroecologia foi “[...] desenvolvida a partir da década de 1970, como consequência de uma busca de suporte teórico para as diferentes correntes de agricultura alternativa que já vinham se desenvolvendo desde a década de 1920" (ASSIS; ROMEIRO, 2002, p. 2).

Diante disso, Assis e Romeiro (2002) fazem uma observação quanto ao entendimento e uso dos termos "agroecologia" e "agricultura orgânica", pois, em função da proximidade que têm, é bem comum que haja uma confusão entre os dois. A agroecologia consiste na ciência que estuda uma forma de estabelecer a base teórica para os movimentos de agricultura alternativa; de outro lado, a agricultura orgânica é um desses movimentos e se concretiza na prática agrícola, ou seja, consiste realmente na forma de trabalhar com o solo, no tratamento do ambiente e na produção sustentável de alimentos de origem orgânica.

Assis e Romeiro (2002) complementam dizendo que esse é um movimento alternativo ao convencional, que se contrapõe ao tradicional modo de trabalhar com a agricultura, o qual faz uso demasiado de insumos agrícolas industrializados. Esse movimento está tendo um reconhecimento cada vez maior e consiste no "[...]rompimento com a monocultura e o redesenho dos sistemas de produção" (2002, p. 2).

De acordo com Campanhola e Valarini (2001), a agricultura orgânica consiste em uma forma de trabalhar que está ligada ao conceito macro de agricultura alternativa e adota princípios de reciclagem dos recursos naturais, como, por exemplo, a prática de compostagem de matéria orgânica por meio de micro-organismos, compostagem por meio do uso de minhocas que produzem o húmus, utilização de fertilizantes biológicos e rotação de culturas na propriedade.

A agricultura orgânica, no entendimento de Codonho (2013, p. 119), “[...] está focada em uma produção que substitui os insumos químicos e tóxicos da agricultura convencional por outros, por assim dizer, mais naturais e não prejudiciais ao meio ambiente e à saúde humana [...]".

Codonho (2013) acrescenta que a agricultura orgânica segue um conjunto de normas e de regras, para produzir e comercializar seus produtos, e tais regras têm aceitação em âmbito nacional e internacional. Para os pequenos agricultores, esta forma de trabalho pode ser vista como uma oportunidade de inserir seus produtos no mercado.

Nesse contexto, Campanhola e Valarini (2001, p. 76) entendem que "[...] a agricultura orgânica é uma opção viável para a inserção dos pequenos agricultores no mercado". Os autores baseiam essa afirmação em alguns argumentos, como o fato de que as "commodities" agrícolas requerem uma produção em grande escala, para compensar a queda nos preços e os custos cada vez maiores, reduzindo as margens de lucratividade do produtor. 
Campanhola e Valarini (2001) fundamentam a afirmação na constatação de que os produtos orgânicos atendem a um segmento de mercado seleto, ou seja, um nicho de mercado específico, que se dispõe a pagar um valor consideravelmente maior por um produto mais saudável, fator esse que não ocorre com as "commodities". A inserção dos pequenos produtores nas redes de comercialização de produtos orgânicos, sob a organização de associações ou cooperativas, é um fenômeno que facilita as ações de marketing e a implantação de selos de qualidade e também a gestão das vendas e da produção.

Ainda, segundo Campanhola e Valarini (2001), a afirmação baseia-se, ainda, em dois fatores que colocam o pequeno agricultor em vantagem, que são a diversificação da produção orgânica e a baixa dependência de insumos externos à propriedade. Para os autores, a diversificação da produção consiste em uma vantagem, porque mantém uma renda estabilizada durante o ano todo, o que reduz a sazonalidade e aumenta a segurança do produtor. "Por sua vez, a menor dependência de insumos externos está associada à menor área cultivada pelos pequenos agricultores e, também, à maior facilidade de manejo dos sistemas produtivos com recursos da própria propriedade" (2001, p. 77).

Em linhas gerais, pode-se dizer que a agricultura orgânica consiste em mais uma alternativa para o agricultor familiar, pois, atualmente, é uma categoria em constante crescimento. Essa categoria oferece facilidades ao pequeno produtor, tendo em vista as vantagens levantadas pelos autores frente ao sistema tradicional de produção.

\section{Gestão de propriedades rurais familiares}

Segundo Chiavenato (2003, p. 2), a gestão ou a administração "[...] trata do planejamento, da organização (estruturação), da direção e do controle de todas as atividades diferenciadas pela divisão de trabalho que ocorram dentro de uma organização", e que consiste em uma "[...] condução racional das atividades de uma organização, seja ela lucrativa ou nãolucrativa".

Martins (2016) entende que, para haver um negócio sustentável, deve-se ter a capacidade de inovar, saber se relacionar com órgãos de pesquisa e de fomento, e saber administrar o seu próprio negócio. Argumenta sobre a gestão na agricultura familiar e expõe em seu trabalho que: "um processo de gestão, envolve um pensamento sistêmico, aprendizado organizacional, liderança, inovação, busca por resultados, conhecimento do mercado, parceiros, enfim, envolve um conjunto de características que determinam a gestão" (MARTINS, 2016, p. 4).

A concepção de Uecker, Uecker e Braun (2005, p. 2) sobre a gestão de propriedades rurais familiares aborda a ideia de que o processo de gestão deve ter início com a mentalidade do administrador, já que as mudanças devem iniciar pela postura adotada frente a uma propriedade rural, o qual passa a desenvolver seu trabalho visando ao lucro; caracterizando, portanto, uma empresa rural. "Suas atitudes e comportamentos irão determinar a passagem de um sistema de produção tradicional para um sistema moderno, operando de forma estratégica". 
O conceito de empreendimento rural envolve fatores que têm fundamental importância para o seu sucesso e devem ser observados no contexto em que a empresa rural se encontra. Deve-se ter em mente que é necessário analisar as oportunidades e os limites do ambiente, inclusive identificar e entender como se comportam os agentes que impactam na produção, desde órgãos governamentais até tendências da região, como, por exemplo, o incentivo às propriedades familiares (UECKER; UECKER; BRAUN, 2005).

Conforme Uecker, Uecker e Braun (2005, p. 6), “[...] também é importante considerar se os agricultores estão diversificando a produção e mudando suas técnicas e em que direção e como estão atuando os comerciantes e as agroindústrias".

Silva e Buss (2011) contribuem para esse pensamento em relação à gestão e enfatizam que os pequenos produtores rurais enfrentam problemas no desempenho de suas atividades, porque, além da falta de conhecimentos de administração, também:

a administração rural se caracteriza por um conjunto de atividades que objetivam o planejamento, organização comando e controle da propriedade rural, provendo subsídios para a tomada de decisão pelo produtor/gestor rural, de modo que esse possa gerenciar as atividades, maximizar a produção, minimizar custos, obtendo, dessa forma, melhores resultados econômico-financeiros (SILVA; BUSS, 2011, p. 163).

A administração das organizações envolve alguns fatores que possuem grande representatividade do ponto de vista econômico, e isso se intensifica no caso de empresas rurais que desenvolvem a prática da agricultura, já que essa prática envolve fatores incontroláveis, ou que fogem ao alcance técnico, reforçando o pensamento de que as estratégias adotadas pelos empreendimentos rurais são dotadas de significativa importância (UECKER; UECKER; BRAUN, 2005).

No entanto, a gestão das propriedades na agricultura familiar apresenta algumas peculiaridades que necessitam ser consideradas. De acordo com Deponti (2014, p. 17), diversos trabalhos apontam para esta situação:

destacando que os agricultores dão mais peso para as atividades do campo em
detrimento das atividades de gestão, que a utilização rotineira de instrumentos de
gestão é exceção na maioria dos estabelecimentos pesquisados; que, quando existem
práticas gerenciais, estes procedimentos são rudimentares e distantes do aceitável e
útili que o nível educacional e a idade avançada dos agricultores, aliada à cultura de
não realizar registros escritos, dificulta a implantação de práticas de gerenciamento;
que a existência e a disponibilidade de ferramentas de gestão não garantem a
utilização destas; que há inadequação das ferramentas disponíveis; que há baixa
qualificação dos técnicos extensionistas em tecnologias de gestão; que há
descapitalização dos agricultores; e que as poucas políticas públicas de estímulo ao
setor não privilegiam os aspectos de gestão.

Percebe-se a importância fundamental que a gestão das propriedades familiares tem para os proprietários, os quais devem administrar fatores intrínsecos à propriedade e aos impactos dos fatores extrínsecos. Nesse sentido, a gestão integrada das práticas de pluriatividade, diversificação da produção e agricultura orgânica pode representar uma alternativa interessante para os agricultores familiares. 


\section{Metodologia}

Esta pesquisa enquadra-se na abordagem qualitativa, pois os métodos utilizados para a pesquisa envolvem obtenção de dados descritivos, a fim de responder ao problema levantado. No tocante ao delineamento dos objetivos da pesquisa, pode-se classificá-la como exploratória. Do ponto de vista dos procedimentos, para este trabalho, utiliza-se o estudo de caso, que se caracteriza pela pesquisa de um caso específico, a fim de aprofundar os conhecimentos acerca do objeto ou fenômeno estudado.

O presente estudo utilizou-se da técnica de amostragem não probabilística, ou seja, intencional, e o caso estudado é uma propriedade localizada no interior da cidade de Santiago, no estado do Rio Grande do Sul. A família, que três anos atrás residia em Torres -RS, passou a observar que os supermercados ofereciam produtos hortifrutigranjeiros geralmente de baixa qualidade aos seus clientes, e decidiu mudar-se para Santiago, onde seus membros iniciaram uma produção voltada para o comércio. A propriedade foi escolhida por se enquadrar nos conceitos de agricultura familiar e por observar traços dos conceitos que envolvem o objeto do estudo pretendido, sejam eles pluriatividade, agricultura orgânica e diversificação da produção.

Após problemas ocorridos com a família, verificaram a necessidade de produzir alimentos orgânicos, e, assim, a empresa foca nesse ramo de produção que proporciona à comunidade a oportunidade de consumir produtos de qualidade e livre de agrotóxicos. Sua ação estratégica está sustentada na missão ${ }^{7}$ de oferecer produtos que tragam qualidade de vida e saúde, garantindo a manutenção do bem-estar, a preços acessíveis, para seus clientes, e na visão ${ }^{8}$ de estar entre os principais produtores de orgânicos do estado e ser referência nesse mercado.

Foi realizada uma entrevista não estruturada com a proprietária e seu filho, em sua propriedade, no mês de junho de 2016, e, com o intuito de auxiliar na coleta de dados, realizou-se também uma observação simples. Adotou-se o método da Grounded Theory, que, segundo Bandeira-de-Mello e Cunha (2003, p. 3), baseia-se na ideia de que a análise ocorre simultaneamente à coleta de dados, por meio da interligação de conceitos teóricos com os resultados que vão sendo obtidos nessa coleta. Essa análise constituiu-se, basicamente, da relação entre os conceitos abordados, as observações realizadas e a fala dos entrevistados. Essa dinâmica instalou-se a partir da construção do projeto de pesquisa, o que provocou a atualização do referencial teórico, na medida em que os dados empíricos foram coletados, por meio da observação e da interpretação dos dados. A entrevista contribuiu com a síntese da análise.

A análise dos resultados baseia-se nos dados coletados por meio da entrevista semiestruturada que foi desenvolvida e da observação simples, realizada na propriedade selecionada para o estudo de caso. Esses resultados foram analisados levando-se em consideração os conceitos dos autores já citados na revisão de literatura pertinente a este trabalho.

\footnotetext{
${ }^{7}$ Dados informados pela proprietária, porém ainda não foram racionalizados de maneira formal.

${ }^{8}$ Idem.
} 


\section{A interação da pluriatividade, da diversificação e da produção orgânica com a gestão rural}

A pesquisa revelou que a propriedade familiar é explorada com a agricultura orgânica para a produção de hortaliças e está iniciando projetos para produção de frutas e criação de peixes. A mão de obra utilizada é da família, porém, eventualmente, utiliza mão de obra terceirizada, para desenvolver trabalhos paralelos à produção, como, por exemplo, cercas, estufas, etc. A área total da família é de 4,5 hectares, porém a área explorada com a agricultura é de 1 hectare.

Baseado nos conceitos já revisados e nos dados coletados, pode-se afirmar que o estabelecimento objeto do estudo de caso enquadra-se na categoria de propriedade familiar destacada na Lei no 4.504 de 1964, já que é explorada pela família, que, eventualmente, utilizase do trabalho de terceiros em sua propriedade, cuja área total não ultrapassa o limite estipulado de quatro (4) módulos fiscais, sendo que, na região estudada, cada módulo representa 35 hectares de área.

Sobre a agricultura familiar, os dados levantados dizem que, além do sustento da família, a produção abastece a merenda escolar do município, duas feiras de orgânicos que ocorrem semanalmente na cidade, três supermercados e um restaurante. Esses dados contribuem com as ideias já citadas sobre a agricultura familiar como sendo o modo pelo qual mais se produz alimentos no Brasil, bem como aquelas que dizem que, na agricultura familiar, o excedente dos produtos da propriedade é comercializado para fins de obtenção de renda (FUNK; BORGES; SALAMONI, 2006).

No que diz respeito à pluriatividade, o grupo familiar é composto por quatro membros: a proprietária, seu filho e seu genro trabalham apenas na propriedade; sua filha, no entanto, trabalha no comércio, embora desenvolva a agricultura na propriedade principalmente no que se refere à produção de brotos. Esse contexto reflete os conceitos de pluriatividade, segundo os quais vem a ser uma combinação de várias ocupações (SCHNEIDER et al., 2006), envolvendo atividades agrícolas e não-agrícolas (SCHNEIDER, 2009), em que pelo menos um membro da família esteja envolvido em atividades estranhas à agricultura (AZAMBUJA, 2006). Os dados observados permitem afirmar que o tipo de pluriatividade que ocorre na propriedade é a intersetorial, já que um membro do grupo familiar está envolvido com o comércio e com a agricultura simultaneamente (SCHNEIDER, 2009).

Sobre a diversificação da produção, a família cria suínos e galinhas, utilizando ovos e outros produtos para consumo próprio. No entanto, para fins comerciais, apenas a produção de hortaliças é utilizada, envolvendo, atualmente, 35 produtos diferentes, o que comprova o conceito de que o produtor familiar retira o máximo de proveito da integração de diversas culturas e criações, de acordo com FUNK (2008).

A pesquisa possibilitou identificar, também, que a agricultura orgânica está sendo muito procurada nas feiras, pois uma gama diversificada de produtos é essencial para quem quer ter opções, impactando a geração de renda. Dessa forma, a estabilidade econômicofinanceira da família depende muito da diversificação e do escalonamento da produção, o que reforça o conceito de que a diversificação da produção orgânica consiste em uma vantagem ao produtor, conforme afirmado por Campanhola e Valarini (2001). 
Os dados levantados com a pesquisa empírica possibilitam que se conclua a ocorrência da diversificação da produção no caso estudado, de tal forma que ilustram os conceitos segundo os quais o produtor não depende de apenas um tipo de cultura (Fantin apud Haas, 2008), e dão ênfase à questão de que a diversificação se constitui numa alternativa para promover o desenvolvimento das propriedades familiares (CARVALHO, 2005).

No contexto da agricultura orgânica, a família produz, por meio de compostagem de produção de húmus originário de minhocas, o adubo para utilização na propriedade, embora, recentemente, tenha passado a comprar adubo orgânico certificado, trazendo à tona a ideia de que essa categoria adota princípios de reciclagem dos recursos naturais (CAMPANHOLA; VALARINI, 2001). O grupo familiar entende que a agricultura orgânica está em alta no momento, em função da qualidade dos produtos que são fornecidos, e vê essa categoria como oportunidade de se inserir no mercado.

A concepção da família em relação à agricultura orgânica reforça os conceitos dos autores estudados, que dizem estar essa agricultura baseada na forma de trabalhar o solo (ASSIS; ROMEIRO, 2002), substituindo os insumos químicos por orgânicos, com fins de produzir alimentos mais saudáveis à população (CODONHO, 2013). Da mesma forma, reforça a ideia de que a agricultura orgânica é uma porta de entrada no mercado para os pequenos produtores e uma forma de se consolidarem nesse mercado.

No que se refere à gestão da propriedade, a família encara o estabelecimento como uma empresa rural e toma as decisões em conjunto no que diz respeito à produção e às decisões estratégicas da propriedade (UECKER; UECKER; BRAUN, 2005). As atividades são informalmente divididas entre os membros da família, de forma que, se uma pessoa é responsável pela produção; outra o será pelos controles administrativo e financeiro; outra, pela logística e comercialização.

A família da propriedade faz um mapa de produção, para planejar, de acordo com os prazos de cada espécie, quando se deve plantar para saber quando se dará a colheita da produção. Esse planejamento é realizado de acordo com a demanda dos consumidores, e a estrutura da sua produção é baseada na qualidade dos produtos, evidenciando o pensamento do planejamento, da organização e da estruturação na condução racional das atividades da propriedade, de acordo com o que Chiavenato (2003) menciona em sua obra.

Os gestores utilizam recursos de informática, principalmente tabelas, para controlar os custos de produção, o retorno das vendas, bem como controles voltados para a produção, que, segundo a entrevistada, fornecem dados para a tomada de decisão em relação ao que plantar, qual a taxa de perda da produção, qual o custo/benefício de cada produto, entre outras informações necessárias às decisões estratégicas da propriedade, o que torna clara a ideia de direção e controle das atividades da organização, trazida por Chiavenato (2003). Tal situação destoa em relação à maioria das propriedades de agricultura familiar avaliadas pelos trabalhos de diversos autores ${ }^{9}$, que destacam a dificuldade de gestão econômico-financeira nos empreendimentos de agricultura familiar.

9 No trabalho, Batalha, Buainain e Souza Filho (2005), os autores, citam diversas experiências: Rezende e Zylbersztajn (1999), Pavarina, Cella e Peres (2003), Lunardi (2000), Castro, Quadros e Dias (2003). 
A pesquisa mostra que a família adota estratégias voltadas para a otimização da produção e à redução de custos (SILVA; BUSS, 2011), e demonstra tal situação com a produção de mudas, que, há algum tempo, teria um custo alto e baixo impacto, mas que hoje, em função do volume de mudas demandado por outros estabelecimentos, faz com que a família julgue mais barato produzir as próprias mudas. Em relação a produtos diferenciados no mercado, a empresa adota a estratégia de produzir aqueles que geralmente não são produzidos na região, embora, segundo a entrevistada, a região tenha uma cultura que acaba direcionando a determinados produtos, sendo necessário um trabalho de conscientização em relação aos benefícios trazidos pelos outros produtos. Pode-se notar claramente que o modo como a família administra a propriedade caracteriza um conjunto de atividades que têm por objetivo o melhor gerenciamento da organização, a fim de facilitar a tomada de decisões (SILVA; BUSS, 2011).

A pesquisa revelou também que a agricultura orgânica agrega mais valor ao produto; além disso, existe uma concepção que vai além dos benefícios ao consumidor e que traz consigo o teor social da sustentabilidade (ASSIS; ROMEIRO, 2002). Em relação à diversificação da produção, a família considera ser elemento essencial, já que a propriedade atua nas feiras do município, e, para esse tipo de mercado, julga-se imprescindível ter uma gama diversificada de produtos, para atender ao maior número de pessoas possível, e consolidar-se como estratégia de sobrevivência (HAAS, 2008).

Quanto à pluriatividade, no contexto em que a propriedade se encontra atualmente, 0 fato de ter um integrante do grupo familiar desenvolvendo trabalho em outro setor da economia e na agricultura, simultaneamente, auxilia à geração de renda. Entretanto, a pesquisa revela que, após a ampliação da área produzida na propriedade, a relação de trabalho fora da empresa será menos lucrativa para essa integrante do que trabalhar diretamente na propriedade, ou seja, os ganhos serão maiores se trabalhar exclusivamente na propriedade, ao invés de fazê-lo em paralelo com o comércio, destacam os entrevistados.

De acordo com a pesquisa, a forma como a família administra faz com que a propriedade se diferencie no mercado, e isso se dá, principalmente, por meio do empreendedorismo e do constante processo de inovação (MARTINS, 2016), carências de outros produtores. Os principais resultados que traduzem esse pensamento são o fato de a propriedade ser referência em produção orgânica familiar na região, produzir alimentos orgânicos em escala maior do que os produtores que, há mais de 20 anos, já o faziam, conforme os entrevistados, assim como ter criado uma associação de produtores de orgânicos no município, que a cada dia integra mais membros à sua força de trabalho e, consequentemente, contribui no desenvolvimento rural, visto que os produtores comercializam sua produção para abastecer a merenda escolar do município e as unidades do exército da região.

Observaram-se na propriedade fortes traços referentes à mentalidade administrativa que o grupo familiar deve ter para gerir o estabelecimento (UECKER; UECKER; BRAUN, 2005). Foi constatado por meio da pesquisa que a propriedade desenvolve suas atividades com base em um planejamento prévio, de forma organizada e controlada, inclusive que os dados obtidos através dos controles são utilizados nas tomadas de decisões da empresa.

A forma como a produção é planejada e organizada possibilita à propriedade minimizar custos, diminuir a sazonalidade, por meio da substituição de algumas culturas por 
outras similares de épocas diferentes, e ter sempre produtos para entregar aos consumidores, de forma a manter sua estabilidade econômico-financeira.

\section{Considerações finais}

Ao final deste artigo, chegou-se a algumas considerações acerca dos resultados da pesquisa, entre as quais se encontra o fato de o caso estudado expor os fenômenos do objeto da pesquisa, cujas características identificam-se com conceitos trazidos pelos autores referenciados. Com a pesquisa, pôde-se alcançar o primeiro objetivo deste trabalho que foi o de definir os conceitos de pluriatividade, de diversificação da produção e de agricultura orgânica, a fim de torná-los mais claros para a investigação.

O segundo objetivo deste estudo foi o de analisar o funcionamento dos sistemas de trabalho desenvolvidos dentro de cada categoria ora definida, com vistas a buscar o entendimento prático de sua concepção, objetivo este alcançado por meio, principalmente, da entrevista realizada com seus proprietários e da observação da propriedade. $O$ entendimento dos conceitos, na sua concepção prática, teve fundamental importância, pois facilitou o processo de análise dos dados, a fim de responder ao problema de pesquisa. A análise dos principais impactos da gestão combinada e integrada dos sistemas de trabalho consistiu-se no terceiro objetivo do estudo e possibilitou chegar às considerações que seguem.

A agricultura orgânica é vista, atualmente, como uma forma de produção alternativa, que busca a sustentabilidade e o bem-estar. Em consequência disso, os produtos originários desse tipo de produção estão sendo, cada vez mais procurados pelos consumidores. Essa tendência consiste em uma oportunidade para o agricultor familiar entrar em um mercado e consolidar-se nele.

Dessa forma, a diversificação da produção assume papel importante nesse mercado, pois quem busca produtos orgânicos geralmente prefere ter diversas opções para consumir, e isso se torna uma vantagem ao produtor que participa desse nicho de mercado. A partir dessa concepção, pode-se deduzir que trabalhar com uma produção diversificada vai suprir a demanda de uma quantidade maior de consumidores, e, consequentemente, vai aumentar a geração de renda do produtor, resultando numa estabilidade econômico-financeira para a família.

Nesse contexto de geração de renda e de estabilidade econômico-financeira, a pluriatividade desempenha papel relevante, pois, no caso estudado, essa categoria gera renda extra para a família. Entretanto, há indícios de que, à medida que a propriedade aumente sua área produzida, o emprego de um membro da família em atividade não agrícola, externa à propriedade, possa se tornar menos vantajoso do que se essa mão de obra fosse empregada exclusivamente na produção agrícola. É importante ressaltar que esses são indícios constatados para este estudo de caso, no qual a ocorrência da pluriatividade intersetorial e o contexto em que a propriedade se insere levam a essas constatações.

O estudo revelou que a gestão integrada das categorias observadas exerce singular importância no que diz respeito à estabilidade econômico-financeira e ao desenvolvimento da propriedade, decorrente do fato de que, para se ter uma produção orgânica diversificada e orientada para o comércio, é necessário que se tenha um planejamento estruturado, com 
escalonamento de produção, com controles que permitam calcular as perdas, os riscos de produção e a relação de custo/benefício entre diferentes produtos.

$\mathrm{O}$ artigo desenvolvido levantou algumas questões que podem ser investigadas em pesquisas futuras, como, por exemplo, o quanto a pluriatividade intersetorial impacta positivamente o desenvolvimento das propriedades familiares, tendo em vista o potencial de crescimento dessas propriedades, ou seja, impacta positivamente, mas o qual o limite? Esse tema é relevante para estudos futuros, inclusive para tratar de questões como a permanência do jovem no campo.

Com a investigação realizada, pretende-se ter contribuído com os estudos realizados por outros autores sobre a temática, trazendo uma nova perspectiva, que propõe a combinação de diferentes práticas em uma mesma propriedade como estratégia para o seu desenvolvimento.

\section{Referências}

ASSIS, Renato Linhares de; ROMEIRO, Ademar Ribeiro. Agroecologia e Agricultura Orgânica: controvérsias e tendências. In: Desenvolvimento e Meio Ambiente, 6, 2002, Curitiba. p. 67-80.

AZAMBUJA, José Luiz Bortoli de. A importância da pluriatividade como estratégia de reprodução da agricultura familiar: o caso da comunidade de Aguapés no município de Osório/RS. Porto Alegre: EMATER/RS-ASCAR, 2006.

BANDEIRA-DE-MELLO, Rodrigo; CUNHA, C.J.C.A. Operacionalizando o método da Grounded Theory nas Pesquisas em Estratégia: técnicas e procedimentos de análise com apoio do software ATLAS/TI. In: Encontro de Estudos em Estratégia, 2003, Curitiba. Disponível em: <http://www.anpad.org.br/diversos/trabalhos/3Es/3es_2003/2003_3ES39.pdf>. Acesso em: 4 maio 2016.

BATALHA, M.O.; BUAINAIN, A.M.; SOUZA FILHO, H.M. Tecnologia de gestão e agricultura familiar. In: BATALHA, M.O. Gestão do agronegócio: textos selecionados. São Carlos: EDUFSCAR, 2005. Disponível em: <http://www2.ufersa.edu.br/portal/view/uploads/setores/241/Tecnologia\%20de\%20Gest\%C3 \%A3o\%20e\%20Agricultura\%20Familiar.pdf>. Acesso em: 19 ago. 2014.

BRASIL. Lei no 4.504, de 30 de novembro de 1964. Dispõe sobre o Estatuto da Terra, e dá outras providências. Diário Oficial da União, Brasília, 30 nov. 1964. Seção 1.

. Lei no 11.326, de 24 de julho de 2006. Estabelece as diretrizes para a formulação da Política Nacional da Agricultura Familiar e Empreendimentos Familiares Rurais. Diário Oficial da União, Brasília, p. 1, 25 jul. 2006. Seção 1.

BROSE, Markus. Agricultura familiar, desenvolvimento local e políticas públicas. Santa Cruz do Sul: EDUNISC, 1999.

CAMPANHOLA, Clayton; VALARINI, Pedro José. A agricultura orgânica e seu potencial para o pequeno agricultor. Cadernos de Ciência \& Tecnologia, v. 18, n. 3, p. 69-101, set./dez. 2001. Disponível em: <http://ciorganicos.com.br/wp-content/uploads/2013/09/8851-29343-1PB.pdf>. Acesso em: 9 ago. 2016. 
CARVALHO, Jaciara Fernanda de. Diversificação Agrícola: uma alternativa para a agricultura familiar. In: Congresso da Sociedade Brasileira de Economia, Administração e Sociologia Rural, XLIII, 2005, Ribeirão Preto. Disponível em: <http://www.sober.org.br/palestra/2/681.pdf>. Acesso em: 20 jun. 2015.

CASTRO, C.C.; QUADROS, G.A.S.; DIAS, M.C. Avaliação do uso de um sistema de gerenciamento de propriedades rurais: estudos de casos na região de Carazinho (RS). Anais do XLI Congresso Brasileiro de Economia e Sociologia Rural. Juiz de Fora. Julho de 2003.

CHIAVENATO, Idalberto. Introdução à Teoria Geral da Administração: uma visão abrangente da moderna administração das organizações. 7. ed. rev. e atual. 6a reimp. Rio de Janeiro: Elsevier, 2003.

CODONHO, Camila Guedes. Ser orgânico: agricultura ecológica e novas ruralidades no sul de Minas Gerais. 2013. 291p. Tese (Doutorado em Ciências Sociais - Instituto de Filosofia e Ciência Humanas) - Universidade Estadual de Campinas, Campinas, 2013.

DEPONTI, C. M. As "agruras" da gestão da propriedade rural pela agricultura familiar. REDES, Revista do Desenvolvimento Regional, Santa Cruz do Sul, v. 19, ed. especial, p. 9-24, 2014. Disponível em: < https://online.unisc.br/seer/index.php/redes/article/download/5150/3555>. Acesso em: 9 ago. 2016.

. Contribuições teóricas brasileiras ao debate da agricultura familiar. In: Revista Gedecon, v. 2, p. 82-102, 2006.

ELLIS, Frank. Diverse Livelihoods and Natural Resources: A Research Context. Institute of Development Studies, England, n. 7, p. 1-16, jan. 2001. Disponível em: <https://www.ids.ac.uk/files/SLSA7.pdf>. Acesso em: 28 jan. 2014.

The Determinants of Rural Livelihood Diversification in Developing Countries. Journal Agricultural Economics, n. 2, p. 289-302, maio 2000.

FUNK, Fabiana. Agricultura familiar diversificada e qualidade de vida: o caso do município de São Pedro do Butiá - Rio Grande do Sul. 2008. 198f. Dissertação (Programa de Pós-Graduação em Desenvolvimento Regional - Mestrado e Doutorado, Área de concentração em Desenvolvimento Regional) - Universidade de Santa Cruz do Sul, Santa Cruz do Sul, 2008.

FUNK, Fabiana; BORGES, Maria A. M.; SALAMONI, Giancarla. Pluriatividade: Uma estratégia de sustentabilidade na agricultura familiar nas localidades de Capão Seco e Barra Falsa 3음 Distrito Rio Grande-RS. Geografia, v. 15, n. 2, p. 51-61, jul./dez. 2006. Disponível em: <http://www.uel.br/revistas/geografia>. Acesso em: 22 maio 2015.

HAAS, Jaqueline Mallmann. Diversificação da Produção no Meio Rural como Estratégia de Sobrevivência: um estudo de caso da região noroeste do Rio Grande do Sul. In: Encontro Nacional da Associação Nacional de Pós-Graduação e Pesquisa em Ambiente e Sociedade ANPPAS, IV, 2008, Brasília. Anais. Brasília: ANPPAS, 2008.

JEAN, B. A forma social da agricultura familiar contemporânea: sobrevivência ou criação da economia moderna. Cadernos de Sociologia, PPGS/UFRGS, Porto Alegre, v. 6, p. 76-89, 1994.

LUNARDI, S.M. Administração da unidade familiar: uma análise do programa de gestão agrícola da extensão rural do Rio Grande do Sul e Santa Catarina na perspectiva dos agricultores.

Dissertação (Mestrado) - Universidade de Lavras do Sul, Minas Gerais, 2000. 
MARTINS, Fabíola Mendes. A Gestão Eficiente e Sustentável da Propriedade Rural Familiar em Laguna (SC). Disponível em: <http://www.uniedu.sed.sc.gov.br/wp-

content/uploads/2014/01/Fabiola-Mendes-Martins.pdf>. Acesso em: 22 maio 2016.

PAVARINA, P.R.J.P.; CELLA, D.; PERES, F.C. A percepção das atividades administrativas: produtores rurais e profissionais da assistência técnica. Anais do XLI Congresso Brasileiro de Economia e Sociologia Rural. Juiz de Fora, 2003.

PIRES, José A. S.; SPRICIGO, Gisele. In: Agricultura Familiar e Ruralidade. O Conceito da Pluriatividade na Agricultura Familiar: São Leopoldo, S/D.

SCHNEIDER, Sergio. A pluriatividade no meio rural brasileiro: características e perspectivas para investigação. In: GRAMMONT, Hubert Carton de; MARTINEZ VALLE, Luciano (Org.).

La pluriactividad en el campo latino-americano. Quito/Equador: Flacso - Serie FORO, 2009. v. 1, p. 132-161.

. Teoria Social, Agricultura Familiar e Pluriatividade. Revista Brasileira de Ciências Sociais: São Paulo, v. 18, n. 51, p. 99-121, fev. 2003.

SCHNEIDER, Sergio et al. A pluriatividade e as condições de vida dos agricultores familiares do Rio Grande do Sul. In: . A Diversidade da Agricultura Familiar. Porto Alegre: UFRGS, 2006. p. 137-165.

SILVA, Paola; BUSS, Ricardo Niehues. A Administração na Pequena Propriedade Rural. Revista São Luis Orione, Araguaína, v. 1, n. 5, p. 149-173, jan./dez. 2011.

STOFFEL, Janete. A Influência da Agricultura Familiar no Desenvolvimento Rural da Região Sul do Brasil. 2013. 290 p. Tese (Doutorado em Desenvolvimento Regional) - Universidade de Santa Cruz do Sul, Santa Cruz do Sul, 2013.

TEDESCO, João Carlos (Org.). Agricultura familiar, realidades e perspectivas. Passo Fundo: EDIUPF, 1999.

UECKER, G. L., UECKER, A. D.; BRAUN, M.B.S. A gestão dos pequenos empreendimentos rurais num ambiente competitivo global e de grandes estratégias. In: XLIII Congresso Brasileiro de Economia e Sociologia Rural - Anais. SOBER, 2005, Ribeirão Preto, 2005. 